\title{
Daily mean temperature and HFMD: risk assessment and attributable fraction identification in Ningbo China
}

\author{
Rui Zhang ${ }^{1} \cdot{\text { Zhehan } \mathrm{Lin}^{2} \cdot \text { Zhen } \mathrm{Guo}^{3} \cdot \text { Zhaorui Chang }^{1} \cdot \text { Ran Niu }^{4} \cdot \text { Yu Wang }}^{5} \cdot$ Songwang Wang ${ }^{1} \cdot$ \\ Yonghong Li $\mathbb{1}^{5}$
}

Received: 21 August 2020 / Accepted: 6 January 2021 / Published online: 5 February 2021

(c) The Author(s) 2021. This article is published with open access

\begin{abstract}
Background Hand, foot, and mouth disease (HFMD) remains a significant public health issue, especially in developing countries. Many studies have reported the association between environmental temperature and HFMD. However, the results are highly heterogeneous in different regions. In addition, there are few studies on the attributable risk of HFMD due to temperature. Objectives The study aimed to assess the association between temperature and HFMD incidence and to evaluate the attributable burden of HFMD due to temperature in Ningbo China.

Methods The research used daily incidence of HFMD from 2014 to 2017 and distributed lag non-linear model (DLNM) to investigate the effects of daily mean temperature (Tmean) on HFMD incidence from lag 0 to 30 days, after controlling potential confounders. The lag effects and cumulative relative risk (CRR) were analyzed. Attributable fraction (AF) of HFMD incidence due to temperature was calculated. Stratified analysis by gender and age were also conducted.

Results The significant associations between Tmean and HFMD incidence were observed in Ningbo for lag 0-30. Two peaks were observed at both low $\left(5-11^{\circ} \mathrm{C}\right)$ and high $\left(16-29^{\circ} \mathrm{C}\right)$ temperature scales. For low temperature scale, the highest CRR was 2.22 (95\% CI: $1.61-3.07)$ at $7^{\circ} \mathrm{C}$ on lag 0-30. For high temperature scale, the highest CRR was 3.54 (95\% CI: $2.58-4.88$ ) at $24{ }^{\circ} \mathrm{C}$ on lag 0-30. The AF due to low and high temperature was $5.23 \%$ (95\% CI: 3.10-7.14\%) and $39.55 \%$ (95\% CI: 30.91-45.51\%), respectively. There was no significant difference between gender- and age-specific AFs, even though the school-age and female children had slightly higher AF values.

Conclusions The result indicates that both high and low temperatures were associated with daily incidence of HFMD, and more burdens were caused by heat in Ningbo.
\end{abstract}

Keywords Hand, foot, and mouth disease (HFMD); Meteorological factors; Temperature; Distributed lag non-linear model (DLNM); Ningbo

Supplementary information The online version contains supplementary material available at https://doi.org/10.1038/s41370021-00291-y.

$\triangle$ Yonghong Li

liyonghong@nieh.chinacdc.cn

$\triangle$ Songwang Wang

wangws@chinacdc.cn

1 Chinese Center for Disease Control and Prevention, Beijing 102206, China

2 China Population Communication Center, Beijing 100013, China

3 Institute of Medical Information/Medical Library, CAMS \& PUMC, Beijing 100020, China

4 National Institute for Nutrition and Health, Chinese Center for Disease Control and Prevention, Beijing 100050, China

5 National Institute of Environmental Health, Chinese Center for Disease Control and Prevention, Beijing 100021, China

\section{Introduction}

Hand, foot, and mouth disease (HFMD) is a common infectious disease in China. It was first reported in New Zealand in 1957 along with the isolation of Coxsackie virus as the pathogen [1]. This emerging infectious disease was then named as HFMD according to its typical symptoms in 1959 [2]. Infants and children under 6 years old are more likely to get this disease, though elder children and adults could also be infected. HFMD can be caused by various enteroviruses, including Coxsackie virus A16 and Enterovirus 71. Main clinical symptoms of HFMD include fever, mouth ulcers, and vesicles on the hands and feet. In most cases, the disease is mild and self-limiting. But a small proportion can rapidly develop neurological and systemic complications, including 
brainstem encephalitis and poliomyelitis-like acute flaccid paralysis [3].

Previous studies have shed light on the effect of meteorological factors such as temperature, relative humidity, and altitude on HFMD [4-9]. However, many studies have shown that the association between the incidence of HFMD and seasons or temperatures varied with different regions. Some areas have the peak once a year, such as in summer in Japan [10, 11], and in autumn in Finland [12]. Two peaks may occur in other regions, such as in summer and autumn in the United Kingdom [13, 14] and Belgium [15]. The incidence trends of HFMD are different in North and South China. In northern China, HFMD outbreaks in June among cities, such as Beijing $[16,17]$ and Hefei [8]. In several cities of southern China, like Kunming [18] and Guangdong [19, 20], the HFMD outbreaks in May and October-November. These discrepancies could arise from various local climatic conditions, differences in socioeconomic status, and the demographic characteristics of different regions. Our understanding of the impact of seasonal and meteorological variables on disease transmission remains limited. Further research is required to study the effects of meteorological variables on the incidence of HFMD.

At present, attributable risk has been used to study the quantitative dependence and regularity between risk factors and morbidity and mortality of infectious diseases. It has transformed factors such as lifestyle, physical, meteorological, and pollution indicators into measurable indicators for predicting the risk of disease or death in the future. An understanding of the temperature contributing to disease burden is critical for determining research priorities and informing national health policy. However, the contribution of temperature to the incidence of HFMD burden has not been quantified in Ningbo.

Therefore, this research aims to analyze the association between daily mean temperature and incidence of HFMD in Ningbo, as well as evaluate the attributable fraction (AF) of HFMD due to temperature. Thus, reliable basis for the prevention and control of HFMD in Ningbo could be provided.

\section{Materials and methods}

\section{Geography}

Ningbo locates in the Southern China and ranges in latitude from $28^{\circ} 51^{\prime}$ to $30^{\circ} 33^{\prime} \mathrm{N}$ and in longitude from $120^{\circ} 55^{\prime}$ to $122^{\circ} 16^{\prime} \mathrm{E}$. It bounds on the east by the East China Sea and Zhoushan Archipelago, on the north by Hangzhou Bay, across which it faces Jiaxing and Shanghai, on the west by Shaoxing, and on the south by Taizhou. Its land area is
$9714 \mathrm{~km}^{2}$, while oceanic territory amounts to $9758 \mathrm{~km}^{2}$. At the end of 2017, the permanent resident population of Ningbo was 8.05 million.

\section{Climate}

Ningbo has a humid subtropical climate with four distinctive seasons, characterized by hot, humid summers and chilly, cloudy and dry winters (with occasional snow). The mean annual temperature is $16.4^{\circ} \mathrm{C}$, with monthly daily averages ranging from $4.7^{\circ} \mathrm{C}$ in January to $28.0^{\circ} \mathrm{C}$ in July. The city receives an average annual rainfall of $1480 \mathrm{~mm}$ and is affected by the plum rains of the Asian monsoon in June, when average relative humidity also peaks.

\section{Data collection}

The daily incidence data of HFMD in Ningbo from January 2014 to December 2017 were applied from the official website of The Data-center of China Public Health Science [21]. The diagnostic criteria of HFMD were based on the clinical criteria set by the Hand, Foot, and Mouth Disease Control and Prevention Guide published by the National Health Commission of the People's Republic of China [22]. To identify vulnerable populations, the data was reclassified by gender (male, female) and age (0-3, 4-5, $\geq 6$ years old).

The daily mean temperature $\left({ }^{\circ} \mathrm{C}\right)$, daily mean relative humidity $(\%)$ and daily precipitation $(\mathrm{mm})$ were observed at Yinzhou station $\left(29^{\circ} 47^{\prime} \mathrm{N}, 121^{\circ} 33^{\prime} \mathrm{E}\right)$, the national meteorological monitoring station in the central city of Ningbo. These data were provided by the China Meteorological Administration.

\section{Methods}

A distributed lag non-linear model (DLNM) with quasiPoisson regression was applied to evaluate the association between daily mean temperature and incidence of HFMD in Ningbo. The DLNM model was defined by the following formula [23]:

$$
\begin{aligned}
& \log \left[E\left(Y_{t}\right)\right]= \alpha+c b\left(\text { Tmean }_{t}, \text { lag }=30\right)+n s\left(\text { time }_{i}, d f=7 / \text { year }\right) \\
&+n s(\text { RHmean }, 3)+\beta \text { DOW } \\
&
\end{aligned}
$$

where $Y_{t}$ represents the expected number of HFMD incidence on day $t . \alpha$ is the intercept. Tmean ${ }_{t}$ is the daily mean temperature on day $t$. $c b$ refers to the crossbasis function, which specifies the exposure-lag-response relationship simultaneously in the exposure-response and lagresponse dimensions; a quadratic B spline $(b s)$ with 4 degrees of freedom $(d f)$ was used for the exposure-response relationship and natural cubic splines (ns) with 4 degrees of freedom for the lag-response relationship. The lag day up to 30 days reflects the maximum lag day of the temperature 
effect. A smooth function of time with 7 degrees of freedom per year was used in the model to control the seasonality and long-term trends. Daily mean relative humidity (RHmean), as potential confounding variables, was modeled as a natural cubic spline $(n s)$ with 3 degrees of freedom. $D O W$ stands for day of the week, which was entered as a categorical variable, and $\beta$ is the coefficient of DOW [23-26].

The reference temperature for the DLNM analysis was identified according to the relationship between daily mean temperature and incidence of HFMD, that is, the temperature, at which the incidence of HFMD had the relative lower risk was identified as the reference temperature for this study. Cumulative relative risks (CRRs) for specific temperature scales under certain lag days were calculated to assess the effects of temperature on the incidence of HFMD.

$\mathrm{AF}$ was calculated to evaluate the incidence burden of HFMD caused by temperature. There are two ways to define AF within the dlnm framework. One is backward perspective, the other is forward perspective. Backward perspective is a commonly used explanation of lag effect in research, but its calculation process is more complicated than forward perspective. The principle and calculation of forward perspective are relatively simple, but the actual risk may be underestimated [26]. In this study, we used backward perspective to calculate AF. The backward AF $b-A F_{x, t}$ at time $t$ were obtained by the following formulas [26]:

$b-A F_{x, t}=1-\exp \left(-\sum_{l=l_{0}}^{L} \beta_{x_{t-l}, l}\right)$

$l_{0}$ and $L$ correspond to minimum and maximum lags, respectively.

Finally, we calculated the empirical confidence interval values through Monte Carlo simulations [27] and the related 2.5th and 97.5th percentiles of multivariate normal distribution were interpreted as $95 \%$ empirical confidence intervals [26].
Stratified analyses by gender and age were also conducted. The statistical significance tests of gender- and agespecific differences were conducted by using the formula below [28]:

$$
\left(\widehat{Q_{1}}-\widehat{Q_{2}}\right) \pm 1.96 \sqrt{S{\widehat{S E_{1}}}^{2}+S{\widehat{E E_{2}}}^{2}}
$$

where $\widehat{Q_{1}}$ and $\widehat{Q_{2}}$ are the estimates for the two categories, and $\widehat{\mathrm{SE}_{1}}$ and $\mathrm{SE}_{2}$ are their respective standard errors.

\section{Sensitivity analysis}

We conducted the collinear diagnosis to see if there is collinearity among daily mean relative humidity (RHmean) and daily precipitation. Sensitivity analysis was performed by changing the $\mathrm{df}$ of RHmean, adjusting and without adjusting RHmean and daily precipitation, respectively.

Data analysis was conducted using $\mathrm{R}$ software 3.6.2 with the package 'dlnm' [23]. The 'dlnm' package was used for fitting DLNM. For all statistical tests, statistical significance as a two-tailed $P<0.05$.

\section{Results}

\section{Descriptive analysis}

Descriptive statistics for the number of HFMD cases based on gender and age, as well as meteorological variables including daily mean temperature, daily mean relative humidity, and daily precipitation are summarized in Table 1. A total of 129,897 HFMD cases from January 2014 to December 2017 were included in our analyses, of which 76,846 $(59.16 \%)$ were male and 53,051 (40.84\%) were female. The group aged 0-3 years, 4-5 years, and aged $\geq 6$ years accounted for $76.43 \%, 17.19 \%$, and $6.38 \%$, respectively. The mean value of daily mean temperature was $17.46^{\circ} \mathrm{C}$, the standard deviation was $8.42{ }^{\circ} \mathrm{C}$, the minimum value was
Table 1 Descriptive statistics of daily incidence of HFMD and meteorological factors in Ningbo, 2014-2017.

\begin{tabular}{llclll}
\hline & Total & Mean \pm SD & Min & Max & Proportion \\
\hline $\begin{array}{l}\text { Daily mean incidence (cases) } \\
\text { Sex }\end{array}$ & 129,897 & $88.91 \pm 76.84$ & 1 & 479 & - \\
Male & & & & & \\
Female & 76,846 & $52.6 \pm 45.76$ & 0 & 302 & $59.16 \%$ \\
Age & 53,051 & $36.31 \pm 31.71$ & 0 & 183 & $40.84 \%$ \\
$0-3$ & & & & & \\
$4-5$ & 99,284 & $67.96 \pm 56.29$ & 1 & 309 & $76.43 \%$ \\
$\geq 6$ & 22,331 & $15.28 \pm 16.83$ & 0 & 124 & $17.19 \%$ \\
Daily mean temperature $\left({ }^{\circ} \mathrm{C}\right)$ & 8282 & $5.67 \pm 6.13$ & 0 & 46 & $6.38 \%$ \\
Daily mean relative humidity $(\%)$ & - & $17.46 \pm 8.42$ & -4.5 & 32.9 & - \\
Daily precipitation $(\mathrm{mm})$ & - & $79.75 \pm 11.18$ & 34 & 100 & - \\
\hline
\end{tabular}


Fig. 1 Decomposition of additive time series of daily incidence of HFMD in Ningbo (from January 2014 to December 2017).

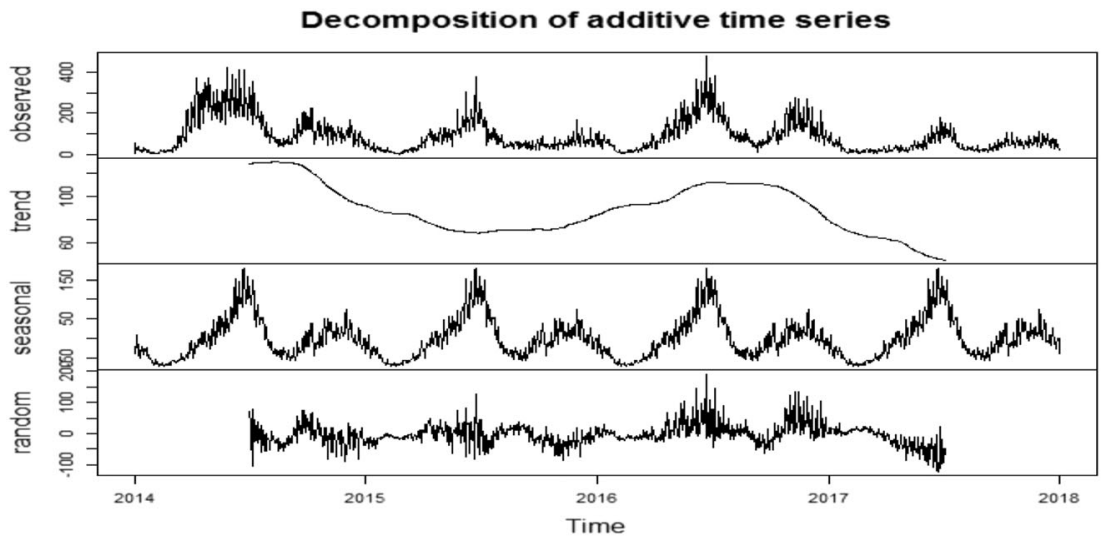

$-4.5^{\circ} \mathrm{C}$, and the maximum value was $32.9{ }^{\circ} \mathrm{C}$. The mean value of daily mean relative humidity was $79.75 \%$, the standard deviation was $11.18 \%$, the minimum value was $34 \%$, and the maximum value was $100 \%$. The mean value of daily precipitation was $5.0 \mathrm{~mm}$, the standard deviation was $14.38 \mathrm{~mm}$, the minimum value was $0 \mathrm{~mm}$, and the maximum value was $276.2 \mathrm{~mm}$.

Figure 1 shows the decomposition analysis of additive time series of daily incidence of HFMD in Ningbo from January 2014 to December 2017, which included the trend of the observed cases, the long-term and seasonal trends and the random variation. The long-term trend showed that the overall incidence of HFMD in Ningbo presented a downward trend from 2014 to 2015 , followed by slowly rising in 2016 and then decreasing in 2017. The seasonal lines showed a strong seasonality that a bimodal seasonal pattern was observed in Ningbo, which was characterized by peaks in HFMD incidence in the summer (June) and early winter (November). And the random line showed the randomness of the data. It was indicated that the dataset of the incidence of HFMD during 2014-2017 in Ningbo was a typical time series and the meteorological variables might be associated with HFMD.

\section{Associations between temperature and HFMD}

Figure 2 shows the CRR of daily HFMD incidence associated with daily mean temperature on lag $0-30$. Analysis of the crude relationship revealed that the potential overall CRR of HFMD had an approximately M-shape with two peaks during $5-11{ }^{\circ} \mathrm{C}$ and $16-29{ }^{\circ} \mathrm{C}$ which was consistent with the bimodal seasonal trend. It was demonstrated in Fig. 2 that the lowest point between the two peaks was $14{ }^{\circ} \mathrm{C}$, so we chose $14{ }^{\circ} \mathrm{C}$ as the reference temperature. The highest risk was at $7{ }^{\circ} \mathrm{C}$ during $5-11^{\circ} \mathrm{C}$ and at $24^{\circ} \mathrm{C}$ during $16-29^{\circ} \mathrm{C}$, so 7 and $24{ }^{\circ} \mathrm{C}$ were chosen as the representative low and high temperatures to calculate relative risk (RR) and CRR, respectively.

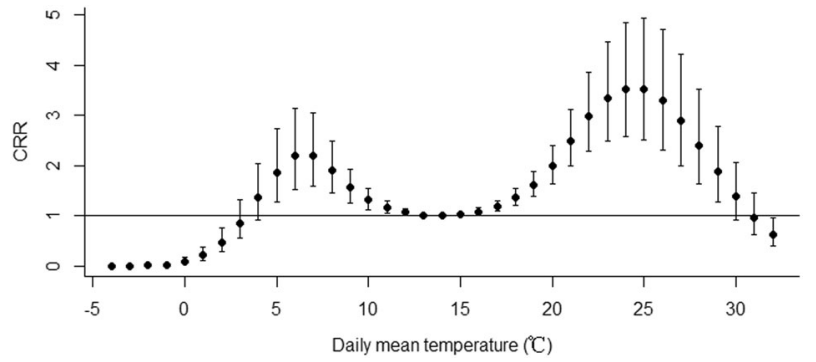

Fig. 2 Cumulative relative risk (CRR) of daily incidence of HFMD associated with daily mean temperature (on lag 0-30 days and reference temperature of $14{ }^{\circ} \mathrm{C}$ ).

Figure 3 shows the RR of daily incidence of HFMD associated with high and low temperatures. It indicated that the temperature-HFMD association was non-linear, immediate, and lasted throughout 30 days lag periods. The RR of daily incidence of HFMD at $7{ }^{\circ} \mathrm{C}$ were more prominent over shorter 10 days lag periods with the highest RR of 1.08 (95\% CI: 1.06-1.10) on lag 3 (Table 2) and diminished over time, whereas the effects at $24{ }^{\circ} \mathrm{C}$ were persistent over longer 30 days lag periods with the highest RR of 1.06 (95\% CI: 1.04-1.07) on lag 14 (Table 2).

It was shown in Table 2 that the $\mathrm{CRR}$ at $7^{\circ} \mathrm{C}$ from lag 0-30 was 2.22 (95\% CI: $1.61-3.07$ ) and the CRR at $24^{\circ} \mathrm{C}$ from lag 0-30 was 3.54 (95\% CI: 2.58-4.88). The results displayed that both gender- and age-specific difference were statistically insignificant. At the low temperature of $7{ }^{\circ} \mathrm{C}$, the CRR of male was 2.50 (95\% CI: 1.77-3.55) and that of female was 1.89 (95\% CI: 1.31-2.71). The CRR of group aged $0-3$ years, $4-5$ years, and $\geq 6$ years was 2.04 (95\% CI: 1.47-2.84), 3.64 (95\% CI: 2.19-6.03), and 1.84 (95\% CI: 0.93-3.63), respectively. At the high temperature of $24^{\circ} \mathrm{C}$, the CRR of male was 3.12 (95\% CI: 2.22-4.40), and that of female was 4.23 (95\% CI: 2.94-6.07). The CRR of group aged $0-3$ years, $4-5$ years, and $\geq 6$ years was 3.31 (95\% CI: 2.40-4.59), 5.08 (95\% CI: 3.08-8.36), and 3.88 (95\% CI: 2.00-7.55), respectively. 
Fig. 3 Relative risk of daily incidence of HFMD associated with low and high temperatures (on lag 0-30 days and reference temperature of $14{ }^{\circ} \mathrm{C}$ ).
Table 2 Relative risks and cumulative relative risks of incidence of HFMD associated with low and high temperatures (reference temperature: $14^{\circ} \mathrm{C}$ ).
Table 3 Attributable fraction of incidence of HFMD due to temperature ( $\mathrm{AF} 95 \% \mathrm{CI}, \%)$.

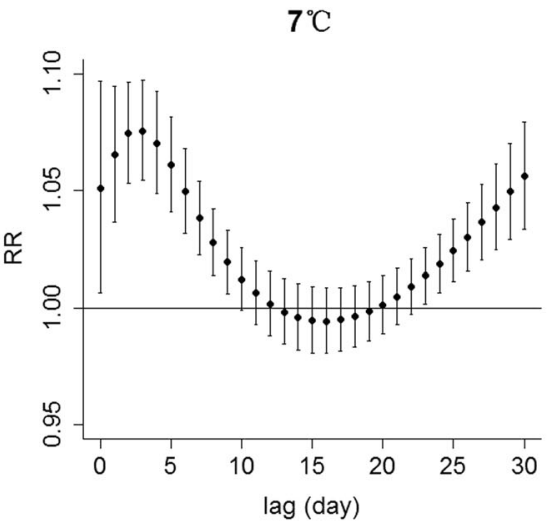

$24^{\circ} \mathrm{C}$

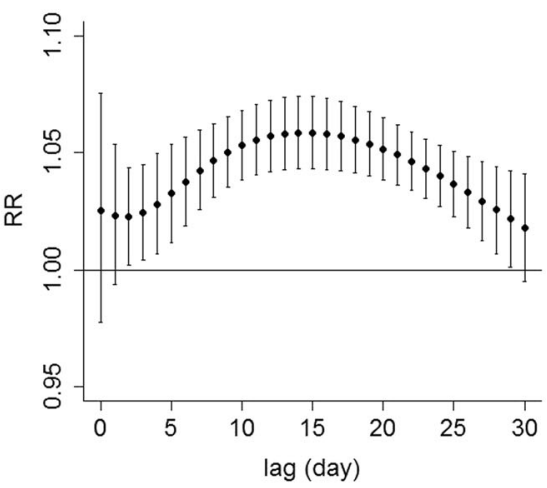

\begin{tabular}{llllll}
\hline & \multicolumn{2}{l}{$\mathrm{RR}(95 \% \mathrm{CI})$} & & $\mathrm{CRR}(95 \% \mathrm{CI})$ \\
\cline { 2 - 3 } \cline { 5 - 6 } & $7{ }^{\circ} \mathrm{C}$, lag 3 & $24{ }^{\circ} \mathrm{C}$, lag 14 & & ${ }^{\circ} \mathrm{C}$, lag $0-30$ & $24{ }^{\circ} \mathrm{C}$, lag $0-30$ \\
\hline $\begin{array}{l}\text { Overall } \\
\text { Sex }\end{array}$ & $1.08(1.06,1.10)$ & $1.06(1.04,1.07)$ & & $2.22(1.61,3.07)$ & $3.54(2.58,4.88)$ \\
Male & $1.08(1.06,1.11)$ & $1.05(1.03,1.07)$ & & $2.50(1.77,3.55)$ & $3.12(2.22,4.40)$ \\
Female & $1.07(1.04,1.09)$ & $1.07(1.05,1.09)$ & & $1.89(1.31,2.71)$ & $4.23(2.94,6.07)$ \\
Age & & & & $3.04(1.47,2.84)$ & $3.31(2.40,4.59)$ \\
$0-3$ & $1.07(1.05,1.09)$ & $1.05(1.04,1.07)$ & & $2.04)$ \\
$4-5$ & $1.11(1.07,1.14)$ & $1.08(1.06,1.11)$ & & $3.64(2.19,6.03)$ & $5.08(3.08,8.36)$ \\
$\geq 6$ & $1.07(1.03,1.12)$ & $1.07(1.04,1.10)$ & & $1.84(0.93,3.63)$ & $3.88(2.00,7.55)$ \\
\hline
\end{tabular}

\begin{tabular}{llll}
\hline Group & Overall & $5-11^{\circ} \mathrm{C}$ & $16-29{ }^{\circ} \mathrm{C}$ \\
\hline $\begin{array}{l}\text { Overall } \\
\text { Sex }\end{array}$ & $45.50(36.21,52.48)$ & $5.23(3.10,7.14)$ & $39.55(30.91,45.51)$ \\
Male & $42.98(31.51,51.23)$ & $5.92(3.60,7.79)$ & $36.61(27.02,44.29)$ \\
Female & $48.26(39.09,54.77)$ & $4.20(1.55,6.47)$ & $43.15(34.21,48.94)$ \\
Age & & & \\
$0-3$ & $43.44(33.14,51.41)$ & $4.67(2.41,6.59)$ & $38.31(29.88,44.79)$ \\
$4-5$ & $53.34(40.91,60.96)$ & $8.36(5.25,10.81)$ & $44.16(34.93,51.28)$ \\
$\geq 6$ & $50.59(26.93,62.89)$ & $3.99(-1.79,7.50)$ & $43.74(26.05,56.20)$ \\
\hline
\end{tabular}

\section{Attributable fraction of HFMD due to temperature}

Table 3 presents the AF of HFMD due to temperature for the overall group as well as gender- and age-specific subgroups. It was shown that the AFs were higher for hot temperatures $\left(16-29^{\circ} \mathrm{C}\right)$ than those for cold temperatures $\left(5-11{ }^{\circ} \mathrm{C}\right)$. The estimated overall $\mathrm{AF}$ due to temperature was $45.50 \%$ (95\% CI: $36.21-52.48 \%$ ). The AF due to cold temperatures $\left(5-11^{\circ} \mathrm{C}\right)$ was $5.23 \%$ (95\% CI: $\left.3.10-7.14 \%\right)$ and the AF due to hot temperatures $\left(16-29^{\circ} \mathrm{C}\right)$ was $39.55 \%$ (95\% CI: $30.91-45.51 \%$ ). The AF of male and female due to temperature was $42.98 \%$ (95\% CI: $31.51-51.23 \%$ ) and 48.26\% (95\% CI: 39.09-54.77\%), respectively. The group aged 4-5 years (AF: 53.34\%, 95\% CI: 40.91-60.96\%) and $\geq 6$ years (AF: 50.59\%, 95\% CI: 26.93-62.89\%) seemed to have higher AF values than the group aged 0-3 years (AF: $43.44 \%$, 95\% CI: $34.14-51.41 \%$ ), but there was no significant difference. The similar trends of the age-specific AFs due to cold and hot temperatures were also observed.

\section{Sensitivity analysis}

The result of collinear diagnosis showed that there was no serious collinearity among RHmean and daily precipitation (correlation coefficient is 0.35 ). The sensitivity analysis results (see Table S1) showed that the CRRs remained unchanged, which indicated that the models were stable. 


\section{Discussion}

We assessed the association between daily mean temperature and daily incidence of HFMD in Ningbo and two peaks were discovered during specific cold $\left(5-11^{\circ} \mathrm{C}\right)$ and hot $\left(16-29^{\circ} \mathrm{C}\right)$ temperatures. What is more, to our best knowledge, for the first time we evaluated the AF of HFMD incidence due to temperature in Ningbo and found that much more disease burden of HFMD could be attributed to high temperature than that attributed to cold temperature. Stratified analysis implied that the occurrence of HFMD of school-age children seemed to be more sensitive to temperature than the group aged $0-3$ years.

In this study, we found that the incidence of HFMD in Ningbo has semiannual peaks, including a higher peak in summer and the lower one in early winter. The result is consistent with the previous studies which demonstrated that HFMD outbreaks once a year in high latitudes regions but twice a year in tropical and subtropical regions [2, 10, 19].

Several previous studies have shed light on the effect of meteorological factors such as temperature on HFMD $[4-9,19,29]$. However, the results have shown that the association between the incidence of HFMD and temperature varied with different regions [24, 29-34]. Chen et al. [35] found that the occurrence of HFMD epidemics was bimodal in Wuhan, one peak occurred when the monthly average temperature was below $15^{\circ} \mathrm{C}$ during autumn-winter and the other occurred when the monthly average temperature exceeds $25^{\circ} \mathrm{C}$ in summer. The study in Guangzhou [19] also found that the association between the daily incidence of HFMD and the daily mean temperature increased rapidly when the daily mean temperature was below $25^{\circ} \mathrm{C}$ but flattened above $25^{\circ} \mathrm{C}$. While our result showed that the risk of HFMD increased during both low temperature from 5 to $11^{\circ} \mathrm{C}$ and high temperatures from 16 to $29^{\circ} \mathrm{C}$ of daily mean temperatures, but declined at both extremely cold $\left(<5^{\circ} \mathrm{C}\right)$ and hot $\left(>29^{\circ} \mathrm{C}\right)$ temperatures. The inconsistency of these findings can be partly attributable to the diversity of methodologies and data sources, but it also implies that the temperature-HFMD relationship might be modified by some location-specific variables. The heterogeneity across studies is still poorly understood which hinder a more comprehensive characterization of the temperature-HFMD relationship.

As some previous studies suggested, our results imply that the effect of temperature on HFMD may involve with complex mechanisms. Some evidential studies found that temperature could affect the breeding, growth, and transmission of pathogens, as well as human behavior [36]. First, HFMD can be transmitted either by exposure to infectious individuals or contaminated environment. During the suitable temperatures (such as $5-11^{\circ} \mathrm{C}$ and $16-29^{\circ} \mathrm{C}$ ), individuals are more likely to have outdoor activities, thereby suitable temperature may increase the chances that susceptible individuals contact with infectious individuals or contaminated environment. Conversely, people will reduce outdoor activities and take some protective measures at extreme temperature. Second, both extremely cold and hot temperatures can reduce the reproduction of pathogens. Temperature is considered as the main factor determining enterovirus inactivation in the environment [37]. According to the previous studies in the laboratory, EV-A71 and CVA16 are lack of a thermostatic mechanism, and their reproduction and survival rates are strongly affected by fluctuations in temperature. The EV-A71 survives at $20^{\circ} \mathrm{C}$ slightly better than at $25^{\circ} \mathrm{C}$ [19], and at $36^{\circ} \mathrm{C}$ is more active than at $39^{\circ} \mathrm{C}$ [38]. Therefore, extremely temperature may shorten the survival time of enterovirus in the environment. All of above might explain the two peaks during specific suitable temperature scales and the dropping down of risk at extreme temperature.

Measures of attributable risk are an integral part of epidemiological analyses, particularly when aimed at the planning and evaluation of public health interventions. It was presented in our results that the overall AF of HFMD incidence due to hot temperatures $(39.55 \%)$ was significantly higher than that due to cold temperatures $(5.23 \%)$. This results indicated that when the temperature is between 16 and $29^{\circ} \mathrm{C}$ in summer in Ningbo, public-health authorities should prepare fully to respond to a possible epidemic of HFMD, including increasing access to health-care resources, the distribution of scientific knowledge to the public, medical staff and public health personnel, the availability of essential medical equipment, active disease surveillance, and the design of other more specific control measures to mitigate the risk of disease transmission.

Although difference of temperature effects between males and females were not statistically significant, the daily incidence of HFMD tended to be higher in males than in females. This result is consistent with other studies $[2,19]$. One possible reason is that boys may be more active and thus have more chances to infect the disease.

It was displayed in our study that the number of the HFMD cases of group aged 0-3 years was the highest. However, the AFs of group aged 4-5 years and $\geq 6$ years were both higher than the AF of group aged 0-3 years, which meant that the occurrence of HFMD of the schoolage children be more susceptible to the ambient temperature. Our results indicated that more attention should also be paid to the school-age children especially by strengthening the hand hygiene and the monitor of symptoms and diseases in kindergarten and primary school especially during periods with specific ambient temperature.

Some limitations of this paper should be acknowledged. First, we used ambient temperature data monitored at a fixed location as most previous epidemiological studies, rather than individual real exposure data, which could lead 
to measurement errors for exposure. Second, as the availability of the data, we did not control the effect of air pollution on the incidence of HFMD. Third, our study focused on Ningbo, a southern city in China. The findings need to be verified in more other cities or regions. However, our results warrant further research on climate change and the incidence of HFMD and provide scientific evidence for the planning of control and prevention of HFMD in Ningbo.

\section{Conclusions}

Both high and low temperatures were associated with daily incidence of HFMD, and more burdens were caused by heat in Ningbo. The results would provide scientific evidence to the threshold setting of HFMD early warning system and help local health departments to provide early warnings to control the risk before reaching its peak and implement effective interventions to reduce the burden of HFMD due to temperature.

Acknowledgements This work was supported by the Special Foundation of Basic Science and Technology Resources Survey from Ministry of Science and Technology of China [2017FY101201, 2017FY101207] and National Science and Technology Major Project [2017ZX10305501-009].

Conflict of interest The authors declare that they have no conflict of interest.

Ethical approval Since no primary data collection was undertaken, no patient or public was involved, no formal ethical assessment or informed consent was required. All data were collected from the official website and all data were fully anonymized.

Publisher's note Springer Nature remains neutral with regard to jurisdictional claims in published maps and institutional affiliations.

Open Access This article is licensed under a Creative Commons Attribution 4.0 International License, which permits use, sharing, adaptation, distribution and reproduction in any medium or format, as long as you give appropriate credit to the original author(s) and the source, provide a link to the Creative Commons license, and indicate if changes were made. The images or other third party material in this article are included in the article's Creative Commons license, unless indicated otherwise in a credit line to the material. If material is not included in the article's Creative Commons license and your intended use is not permitted by statutory regulation or exceeds the permitted use, you will need to obtain permission directly from the copyright holder. To view a copy of this license, visit http://creativecommons. org/licenses/by/4.0/.

\section{References}

1. Robinson CR, Doane FW, Rhodes AJ. Report of an outbreak of febrile illness with pharyngeal lesions and exanthem: Toronto, summer 1957; isolation of group A Coxsackie virus. Can Med Assoc J. 1958;79:615-21.
2. Zhu Q, Hao Y, Ma J, Yu S, Wang Y. Surveillance of hand, foot, and mouth disease in mainland China (2008-2009). Biomed Environ Sci. 2011;24:349-56.

3. Ooi MH, Wong SC, Lewthwaite P, Cardosa MJ, Solomon T. Clinical features, diagnosis, and management of Enterovirus 71. Lancet Neurol. 2010;9:1097-105.

4. Zhang X, Xu C, Xiao G. Spatial heterogeneity of the association between temperature and hand, foot, and mouth disease risk in metropolitan and other areas. Sci Total Environ. 2020;713:136623.

5. Ji X, Huang L, Song J, Fei C, Liu J, Liu H. Short-term effects of meteorological factors, air pollution, and sunspot on childhood hand, foot, and mouth disease in Tianjin, China: a new time series regression, 2014-2018. Environ Sci Pollut Res Int. 2020. https://doi.org/10.1007/s11356-020-09794-x.

6. Guo T, Liu J, Chen J, Bai Y, Long Y, Chen B, et al. Seasonal distribution and meteorological factors associated with hand, foot, and mouth disease among children in Xi'an, Northwestern China. Am J Trop Med Hyg. 2020;102:1253-62.

7. Gu S, Li D, Lu B, Huang R, Xu G. Associations between ambient air pollution and daily incidence of pediatric hand, foot and mouth disease in Ningbo, 2014-2016: a distributed lag nonlinear model. Epidemiol Infect. 2020;148:e46.

8. Deng J, Gao X, Xiao C, Xu S, Ma Y, Yang J, et al. Association between diurnal temperature range and outpatient visits for hand, foot, and mouth disease in Hefei, China: a distributed lag nonlinear analysis. Environ Sci Pollut Res Int. 2020. https://doi.org/ 10.1007/s11356-020-09878-8.

9. Bo Z, Ma Y, Chang Z, Zhang T, Liu F, Zhao X, et al. The spatial heterogeneity of the associations between relative humidity and pediatric hand, foot and mouth disease: evidence from a nationwide multicity study from mainland China. Sci Total Environ. 2020;707:136103

10. Onozuka D, Hashizume M. The influence of temperature and humidity on the incidence of hand, foot, and mouth disease in Japan. Sci Total Environ. 2011;s 410-411:119-25.

11. Sumi A, Toyoda S, Kanou K, Fujimoto T, Mise K, Kohei Y, et al. Association between meteorological factors and reported cases of hand, foot, and mouth disease from 2000 to 2015 in Japan. Epidemiol Infect. 2017;145:2896-911.

12. Blomqvist S, Klemola P, Kaijalainen S, Paananen A, Simonen ML, Vuorinen T, et al. Co-circulation of coxsackieviruses A6 and A10 in hand, foot and mouth disease outbreak in Finland. J Clin Virol. 2010;48:49-54.

13. Bendig JW, Fleming DM. Epidemiological, virological, and clinical features of an epidemic of hand, foot, and mouth disease in England and Wales. Commun Dis Rep CDR Rev. 1996;6:R81-86.

14. Sinclair C, Gaunt E, Simmonds P, Broomfield D, Nwafor N, Wellington L, et al. Atypical hand, foot, and mouth disease associated with coxsackievirus A6 infection, Edinburgh, United Kingdom, January to February 2014. Eur Surveill. 2014;19:20745.

15. Druyts-Voets E. Epidemiological features of entero non-poliovirus isolations in Belgium 1980-94. Epidemiol Infect. 1997;119:71-77.

16. Liu XF, Sun XM, Sun XW, Yang YQ, Huang CH, Wen H. Epidemiological study on hand, foot and mouth disease in Tongzhou District, Beijing, 2013-2017. J Int Med Res. 2019;47:2615-25.

17. Dong W, Li X, Yang P, Liao H, Wang X, Wang Q. The effects of weather factors on hand, foot and mouth disease in Beijing. Sci Rep. 2016;6:19247.

18. Ma S, Zhang Y, Du C, Yang T, Liu Q, Pan Y, et al. Dynamic constitution of the pathogens inducing encephalitis in hand, foot and mouth disease in Kunming, 2009-2011. Jpn J Infect Dis. 2015;68:504-10.

19. Chen C, Jiang Q, Song Z, Li Y, Wang H, Lu Y, et al. Influence of temperature and humidity on hand, foot, and mouth disease in Guangzhou, 2013-2017. J Int Med Res. 2020;48:300060520929895. 
20. Zhang H, Yang L, Li L, Xu G, Zhang X. The epidemic characteristics and spatial autocorrelation analysis of hand, foot and mouth disease from 2010 to 2015 in Shantou, Guangdong, China. BMC Public Health. 2019;19:998.

21. National Population and Health Science Data Sharing Platform: The Data-center of China Public Health Science. http://www. phsciencedata.cn/Share/en/index.jsp.

22. National Health Commission of the People's Republic of China. Hand, Foot and Mouth Disease Control and Prevention Guide. http://en.nhc.gov.cn/.

23. Gasparrini A. Distributed Lag Linear and Non-Linear Models in R: The Package dlnm. J Stat Softw. 2011;43:1-20.

24. Su X, Cheng Y, Wang Y, Liu Y, Li N, Li Y, et al. Regional temperature-sensitive diseases and attributable fractions in China. Int J Environ Res Public Health. 2019;17:184.

25. Liu Z, Tong MX, Xiang J, Dear K, Wang C, Ma W, et al. Daily temperature and bacillary dysentery: estimated effects, attributable risks, and future disease burden in 316 Chinese cities. Environ Health Perspect. 2020;128: 057008.

26. Gasparrini A, Leone M. Attributable risk from distributed lag models. BMC Med Res Methodol. 2014;14:55.

27. Greenland S. Interval estimation by simulation as an alternative to and extension of confidence intervals. Int J Epidemiol. 2004; 33:1389-97.

28. Zeka A, Zanobetti A, Schwartz J. Individual-Level Modifiers of the Effects of Particulate Matter on Daily Mortality. Am J Epidemiol. 2006;163:849-59.

29. Xu C, Zhang X, Wang L, Zhou Y, Xiao G, Liao J. Effects of temperature fluctuations on spatial-temporal transmission of hand, foot, and mouth disease. Sci Rep. 2020;10:2541.
30. Xing W, Liao Q, Viboud C, Zhang J, Sun J, Wu JT, et al. Epidemiological characteristics of hand-foot-and-mouth disease in China, 2008-2012. Lancet Infect Dis. 2014;14:308.

31. Qi H, Li Y, Zhang J, Chen Y, Guo Y, Xiao S, et al. Quantifying the risk of hand, foot, and mouth disease (HFMD) attributable to meteorological factors in East China: a time series modelling study. Sci Total Environ. 2020;728:138548.

32. Gu J, Liang L, Song H, Kong Y, Ma R, Hou Y, et al. A method for hand-foot-mouth disease prediction using GeoDetector and LSTM model in Guangxi, China. Sci Rep. 2019;9:17928.

33. Du Z, Lin S, Marks T, Zhang W, Deng T, Yu S, et al. Weather effects on hand, foot, and mouth disease at individual level: a case-crossover study. BMC Infect Dis. 2019;19:1029.

34. Coates SJ, Davis MDP, Andersen LK. Temperature and humidity affect the incidence of hand, foot, and mouth disease: a systematic review of the literature-a report from the International Society of Dermatology Climate Change Committee. Int $\mathrm{J}$ Dermatol. 2019;58:388-99.

35. Chen B, Sumi A, Toyoda SI, Hu Q, Zhou D, Mise K, et al. Time series analysis of reported cases of hand, foot, and mouth disease from 2010 to 2013 in Wuhan, China. BMC Infect Dis. 2015;15:495.

36. Wang P, Goggins WB, Chan EYY. Hand, foot and mouth disease in Hong Kong: a time-series analysis on its relationship with weather. PLoS One. 2016;11:e0161006.

37. Bertrand I, Schijven JF, Sanchez G, Wyn-Jones P, Ottoson J, Morin T, et al. The impact of temperature on the inactivation of enteric viruses in food and water: a review. J Appl Microbiol. 2012;112:1059-74.

38. Arita M, Shimizu H, Nagata N, Ami Y, Suzaki Y, Sata T, et al. Temperature-sensitive mutants of Enterovirus 71 show attenuation in cynomolgus monkeys. J Gen Virol. 2005;86:1391-401. 